\title{
US AIDS chief lays out priorities
}

The new head of the US President's Emergency Plan for AIDS Relief (PEPFAR) takes the reins of the sometimes controversial programme just as the global economic slump has made the job more difficult than ever.

The Senate confirmed physician Eric Goosby as US global AIDS coordinator on 19 June. Goosby was deputy director of the White House Office of National AIDS Policy during the Clinton administration, and then chief executive officer of the non-profit Pangaea Global AIDS Foundation in San Francisco, California.

Doctors and advocates hope that Goosby will expand PEPFAR's success in delivering AIDS treatment and services while ditching less favoured parts of the programme, such as its focus on prevention by the ABC strategy abstain, be faithful, use condoms.

"He is incredibly well-grounded in the prevention and treatment issues facing the developing world," says Christine Lubinski, vice-president for global health at the Infectious Diseases Society of America in Arlington, Virginia. "But he has got an enormous challenge ahead of him."

In May, advocates called President Barack Obama's global health request of $\$ 63$ billion over six years "meager", saying it broke his campaign pledge to provide $\$ 1$ billion a year in new spending for PEPFAR. The plan spent $\$ 18.8$ billion between 2003

\section{"Goosby has got an} enormous challenge ahead of him." for us," Goosby acknowledges. He hopes to shift PEPFAR's focus away from US non-governmental organizations and towards helping aid-recipient governments set their priorities.

His other main priority is prevention. PEPFAR has been criticized for focusing on $\mathrm{ABC}$ because it fails to help many groups at risk in developing nations, such as married women. Goosby says PEPFAR's prevention efforts must be and 2008, making it the largest aid programme for one disease.

The recession has forced some aid recipients to scale back. In February, Botswana - which has received more than $\$ 300$ million from PEPFAR — said that after 2016 it might stop enrolling patients in its programme to provide free medications. And in May, Tanzania, a recipient of $\$ 828$ million from PEPFAR, said it would shrink its AIDS programmes by $25 \%$.

"The sustainability issue is of high concern more sustained and aggressive, should target high-risk groups and should broaden their focus - by, for instance, making condoms and reproductive-health services more widely available.

These priorities are encouraging to doctors and advocates such as Paul Volberding, vicechair of medicine at the University of California, San Francisco. "I think that there will be some big changes," he says.

Erika Check Hayden 